\title{
Study and Choice of Water Saturation Test Method for Tight Sandstone Gas Reservoirs
}

\author{
Cheng Liu ${ }^{1,2 *}$, Litao Ma ${ }^{1,2}$, Xueqing Liu ${ }^{1,2}$, Yangbing $L^{1,2}{ }^{1,}$ Bo Zhang ${ }^{1,2}$, Dazhong $\operatorname{Ren}^{3,4}$, \\ Dengke Liu ${ }^{5}$ and Xin Tang ${ }^{6}$
}

${ }^{1}$ CNOOC EnerTech-Drilling \& Production Co., Tianjin, China, ${ }^{2}$ Key Laboratory for Exploration and Development of Unconventional Resources, CNOOC Energy Technology \& Services Limited, Tianjin, China, ${ }^{3}$ College of Petroleum Engineering, Xi'an Shiyou University, Xi'an, China, ${ }^{4}$ Shaanxi Key Laboratory of Advanced Stimulation Technology for Oil \& Gas Reservoirs, Xi'an, China, ${ }^{5}$ School of Human Settlement and Civil Engineering, Xi'an Jiaotong University, Xi'an, China, ${ }^{6}$ School of Civil Engineering, Chongqing Three Gorges University, Chongqing, China

OPEN ACCESS

Edited by:

Wei Wang,

Hohai University, China

Reviewed by:

Yong Li,

China University of Mining and

Technology, Beijing, China

Sujata Tarafdar,

Jadavpur University, India

Xuehui Han,

China University of Petroleum (East

China), China

*Correspondence:

Cheng Liu

liucheng14@cnooc.com.cn

Specialty section:

This article was submitted to

Interdisciplinary Physics,

a section of the journal

Frontiers in Physics

Received: 12 December 2021

Accepted: 17 January 2022

Published: 03 March 2022

Citation:

Liu C, Ma L, Liu X, Li Y, Zhang B, Ren D, Liu D and Tang X (2022) Study and Choice of Water Saturation Test

Method for Tight Sandstone

Gas Reservoirs.

Front. Phys. 10:833940.

doi: 10.3389/fphy.2022.833940
This study aims at investigating the applicability of the commonly used water saturation test methods such as distillation extraction method, nuclear magnetic resonance (NMR) method, constant weight method, and Coulomb method in the water saturation test of tight sandstone gas reservoirs. The above methods were studied and optimized to overcome the difficulties of low water content determination caused by low porosity, low permeability, small pore throat, high capillary force, and high bound water saturation of tight sandstone, to obtain relatively accurate water saturation data. The results showed that the water content data determined by the constant weight method were consistent with the known water content saturation, and the average error was 3.6\%. By shortening the echo interval, the average error of water content saturation tested by the NMR method for tight sandstone samples was $4.8 \%$. The two methods of the distillation method and Coulomb method had large errors, and both failed to meet the requirements of water saturation determination of tight sandstone, of which the average error of the former was $27.9 \%$ and the average error of the latter was $50.7 \%$. Therefore, for tight sandstone, the constant weight method and NMR method were recommended to be used for water content saturation testing, and the distillation extraction method and Coulomb method were not recommended. The research results provided a new method for the accurate determination of water content saturation in tight sandstone gas reservoirs.

Keywords: tight sandstone, water saturation, constant weight method, distillation extraction method, Coulomb method, nuclear magnetic resonance method

\section{INTRODUCTION}

The water saturation of tight sandstone gas reservoirs is a key parameter for reservoir evaluation, and its accuracy is directly related to the reliability of reservoir calculation results. The methods of water saturation evaluation can be divided into direct determination method and indirect determination method. The direct methods include distillation extraction method, Coulomb method, dry distillation method, chromatographic method, nuclear magnetic resonance method, and microwave method [1-11]. In addition to the commonly used saturation logging interpretation method [12-14] and rock physical model interpretation method [15], the indirect method also includes saturation model interpretation method based on digital core technology [16, 17]. 

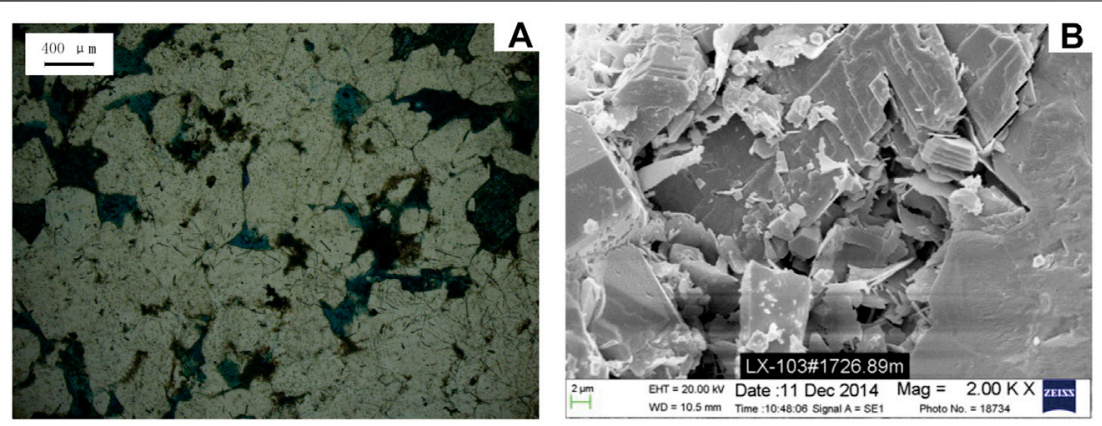

FIGURE 1 | The development and structure of pores of dense sandstone: (A) the development of pores based on microelectron microscopy, and (B) the structure of pores based on field emission scanning electron microscopy.

However, tight sandstone reservoirs are characterized by low porosity, low permeability, narrow pore throat, high capillary force, and high saturation of bound water [18-22]. The water content in the rock is low, and high accuracy of water content determination is required. The currently used methods of water saturation testing include constant weight method (an optimized method based on dry distillation), distillation extraction method, Coulomb method, and NMR method. Different reservoirs have different requirements for experimental test parameters. Although the commonly used methods have specific applicability, they have disadvantages. The constant weight method is prone to clay water precipitation when the test temperature is too high $[2,23]$, which results in abnormally large values of water saturation and leads to great difficulty in reservoir water saturation determination. The distillation extraction method has relatively low metering accuracy, and the water evaporation rate in dense cores is low [11]. The Coulomb method is commonly used in conventional oil and gas reservoirs, and the extraction degree is relatively low for low-permeability as well as dense reservoirs, which affects the experimental accuracy. The test results of water saturation by NMR method are influenced by reservoir factors such as lithology and pore structure, but also by measurement parameters such as echo interval $\mathrm{T}_{\mathrm{E}}$ and waiting time $\mathrm{T}_{\mathrm{W}}$, the larger the echo interval $T_{E}$ is, the larger the error of the collected data is. When TW is not long enough, the movable fluid part with long vertical relaxation time cannot be fully recovered and the full pore fluid signal is not obtained, different reservoirs have different requirements for parameters [24-26]. Therefore, it is necessary to systematically study the test method of water saturation for tight sandstone and carry out method optimization and parameter optimization to meet the demands for water saturation determination, so as to provide a new method for the accurate determination of water saturation in tight sandstone gas reservoirs and accurate data support for tight gas reservoir evaluation.

\section{SAMPLES AND METHODS}

\subsection{Samples}

In this paper, 49 tight sandstone samples from Linxing block in the eastern edge of Ordos Basin were selected to carry out water saturation testing by distillation extraction method, Coulomb method, constant weight method, and nuclear magnetic resonance method, respectively. The samples were dense, poor in physical properties, and highly non-homogeneous, and the connected pores were poorly developed, as shown in Figure 1, which had reference value for the reliability of the test method. In Figure 1A, the mineral particles are filled with a large number of gap fillers, and the pores are mostly independent small pores. In Figure 1B, the pore scale is mostly micro- and nanoscale, and the pore morphology is complex. The porosity of the samples ranged from $2.6 \%$ to $16.3 \%$, with an average of $9.5 \%$, and permeability ranged from 0.0533 to $27.8 \mathrm{mD}$, with an average of $1.99 \mathrm{mD}$, as shown in Supplementary Table S1. Therefore, the rock has low water content and poor mobility.

\subsection{Constant Weight Method}

The determination of water saturation by constant weight method is to dry tight sandstone samples to constant weight at a certain temperature. According to Recommended Practices for Core Analysis, for samples with low clay content, the experimental temperature requirement is $116^{\circ} \mathrm{C}$ using a conventional oven and $90^{\circ} \mathrm{C}$ using a vacuum oven, and the drying time is generally more than $4 \mathrm{~h}$. Finally, the water saturation can be calculated using the mass of the sample before and after drying, the water density of the formation, and the pore volume of the rock. This experimental study was carried out using a conventional oven.

\subsection{Distillation Extraction Method}

The distillation extraction method was applied by use of a Dean Stark extraction device to heat toluene to boiling temperature, through which the water in the rock sample will be distilled out, and the volume of water will be measured. The minimum scale index value of the water trap is $0.05 \mathrm{ml}$, and the distillation extraction time is more than $48 \mathrm{~h}$. The experiment can be stopped only if there is no change in the volume of water collected within $24 \mathrm{~h}$, and then the pore volume of the sample was tested to calculate the water saturation of the rock.

\subsection{Coulomb Method}

The Coulomb method, also known as Karl Fischer titration method, is a method of moisture measurement using the 

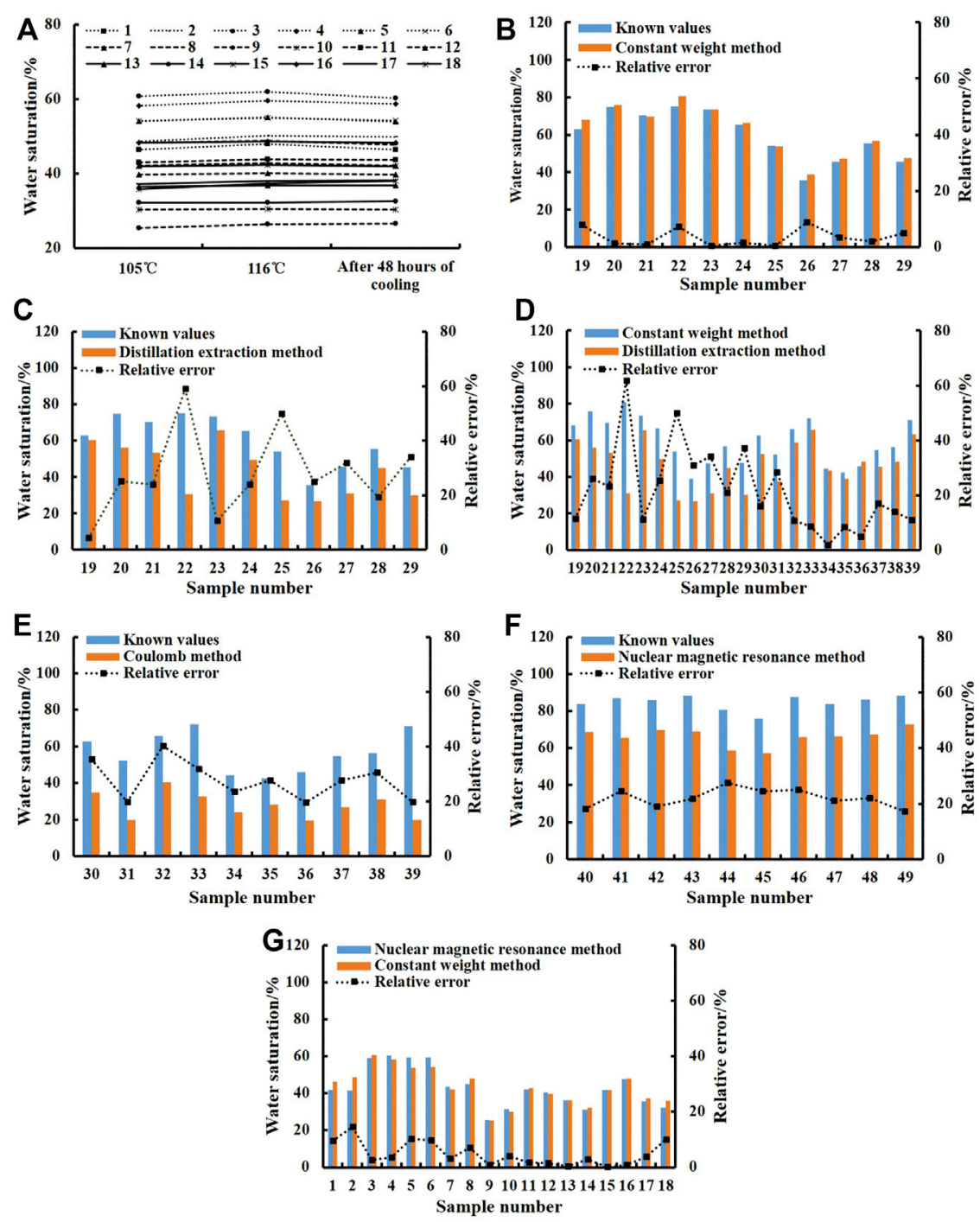

FIGURE 2 | The test results of water saturation by different methods: (A) the relationship of drying temperature and water saturation, (B) constant weight method, (C) distillation extraction method, (D) distillation extraction method vs. constant weight method, (E) Coulomb method, (F) the water saturation test error of core based on normal NMR, and (G) the water saturation test error of core based on the optimized nuclear magnetic resonance method.

principle of chemical reaction; the equipment used is a Coulomb titrator. In this experiment, $20 \mathrm{~g}$ of core sample was put into a mortar, $20 \mathrm{ml}$ of ethanol was drawn into the mortar, and the core was quickly ground to make it mix with ethanol. After the rock was fully ground, the mortar was slightly tilted for $1 \mathrm{~min}$. After the mixed liquid was stratified, 3-5 $\mathrm{ml}$ of the upper clear liquid was aspirated using a syringe for sealing and storing. Finally, the moisture was measured using a Coulomb titrator calibrated.

\subsection{Nuclear magnetic resonance method}

The determination of water saturation by the NMR method is to detect the hydrogen signal of water in rock based on the signal generated by hydrogen nuclear magnetic moment, so as to invert the water saturation value. Firstly, the samples containing formation water were tested on the machine to obtain NMR signal intensity at different $\mathrm{T}_{2}$ relaxation times. Then, the sample porosity is calculated based on the curve calibrated from the signal amount and porosity of the specimen, and the NMR porosity of the sample is obtained. Finally, the water saturation of the NMR method is obtained by calculating the ratio of NMR porosity to helium porosity.

\section{RESULTS AND DISCUSSION}

\subsection{Constant Weight Method}

The experiment of water saturation determination by constant weight method is easy to operate, and the drying temperature and time are the main factors affecting the experimental results. The experimental results of 22 pieces of fresh tight sandstone showed 
that the water saturation of tight sandstone remained stable when the drying temperature reaches above $105^{\circ} \mathrm{C}-116^{\circ} \mathrm{C}$ as required by Recommended Practices for Core Analysis, and the drying time is $8 \mathrm{~h}$ for each temperature point; after that, the moisture in the rocks remained almost unchanged after the samples were placed in the desiccator for $48 \mathrm{~h}$. The saturation value fold line was almost flat for each sample, as shown in Figure 2A. This indicates that the current drying experimental conditions have been able to meet the testing accuracy of water saturation in tight sandstone.

Eleven dense sandstones were selected for quantitative saturation using simulated formation water, and the porosity of the samples ranged from $2.6 \%$ to $10.8 \%$. The water saturation determined by the constant weight method was basically consistent with the known water saturation, and the relative error ranged from $0.36 \%$ to $8.87 \%$, with an average of $3.58 \%$; the fold line had little undulation, as shown in Figure 2B. This indicates that the water saturation measured by the constant weight method is highly accurate and can be used as a reference value for the determination of water content in the core.

\subsection{Distillation extraction method}

Eleven samples were selected for artificial saturation and distillation extraction experiments, and the porosity of the samples ranged from $2.6 \%$ to $10.8 \%$, with an average of $7.1 \%$, and the experiments were conducted according to the experimental conditions recommended by Recommended Practices for Core Analysis. The experimental results showed that some of the tight sandstones were distilled and extracted for more than $60 \mathrm{~h}$ before the volume of collected water could be constant, but the relative errors ranged from $4.2 \%$ to $59.0 \%$ with an average of $27.9 \%$ when compared with the constant weight method, and relative error values had significant fluctuations in the fold, as known in Figure 2C. The relative error of seventy percent samples was greater than $20 \%$. The distillation extraction method can only determine the water content of $41.0 \%-95.8 \%$ in the pores of dense sandstone, with an average value of $72.1 \%$.

Twenty-one fresh samples were selected for the determination of water saturation by distillation extraction method; the porosity of fresh samples ranged from $9.1 \%$ to $16.3 \%$, with an average of $14.0 \%$, and the permeability ranged from 1.77 to $6.99 \mathrm{mD}$, with an average of $3.21 \mathrm{mD}$. The physical conditions were relatively good, and the saturation of the distillation extraction method was lower than that of the constant weight method, with an average error of $12.8 \%$, which was relatively small compared with that of the reservoir with poor physical conditions, as shown in Figure 2D. Therefore, for tight sandstone samples, this distillation extraction method is not recommended because of the large error, and the worse the physical properties, the larger the error.

\subsection{Coulomb Method}

As a method of water saturation test, the Coulomb method has a good application in medium-high-permeability reservoirs [6]. During the experiment, the degree of volatilization of the mixture is closely related to the grinding time. For tight sandstone, the grinding is more difficult; the longer the grinding time is, the more the mixture volatilizes, which may affect the accuracy of the water saturation test.

Ten tight sandstones (the porosity ranging from $10.7 \%$ to $16.3 \%$ with an average of $14.2 \%$ ) were crushed to extract water from the rocks. The water content of the mixture was measured by the calibrated Coulomb instrument. The relative error of the measured water saturation compared to the known water saturation ranged from $35.8 \%$ to $72.3 \%$, with an average error of $50.7 \%$, and the fold undulation was significant, as shown in Figure 2E. This indicates that the Coulomb method cannot meet the requirements of water saturation determination of dense sandstone. The error of this method mainly originates from the pretreatment process of rock samples.

\subsection{Nuclear Magnetic Resonance Method}

When the reservoir geological factors are relatively stable, the experimental parameters of the NMR method have an important influence on the water saturation test [24]. In NMR logging, waiting time $\mathrm{T}_{\mathrm{W}}$ and echo interval $\mathrm{T}_{\mathrm{E}}$ are important acquisition parameters. The echo interval $\mathrm{T}_{\mathrm{E}}$ of MRIL which is the main NMR logger serving Chinese oil and gas fields is desirable at a minimum of $0.6 \mathrm{~ms}$; while the $\mathrm{T}_{\mathrm{E}}$ of CMR series is desirable at a minimum of $0.2 \mathrm{~ms}$, and the waiting time $\mathrm{T}_{\mathrm{W}}$ of MRIL can be $8,9.5$, or $12 \mathrm{~s}$, the minimum can be $20 \mathrm{~ms}$ [26-28]. Xiao et al. [26] concluded that NMR porosity agrees well with conventional porosity when the echo interval is less than $0.35 \mathrm{~ms}$, suggesting that the echo interval of continental reservoirs in China should be $0.3 \mathrm{~ms}$.

The parameters set by the conventional NMR test were adopted to measure the water saturation of tight sandstones, and according to the characteristics of the tight sandstone reservoir with small pore development, $\mathrm{T}_{\mathrm{E}}$ was taken as $0.6 \mathrm{~ms}$ and $\mathrm{T}_{\mathrm{W}}$ was taken as $8 \mathrm{~s}$. The known water saturation of the sample is between $76.0 \%$ and $88.1 \%$, the water saturation measured by the NMR method is between $57.2 \%$ and $72.9 \%$, the relative error is between $17.2 \%$ and $27.4 \%$, and the average is $22.0 \%$, as shown in Figure $\mathbf{2 F}$. This indicated that the conventional NMR test parameters did not apply to tight sandstone reservoirs.

Tight sandstone is dominated by small pores, resulting in a weak signal and poor signal-to-noise ratio of fluid in the pores collected by NMR, resulting in large experimental errors. Short waiting time will lead to the loss of signal in large pores, and the large echo interval will lead to the loss of signal in small pores [27]. Therefore, it is necessary to optimize the parameters, shorten the echo interval, and choose a reasonable waiting time, and thus improve the MRI test accuracy.

The $\mathrm{T}_{2}$ relaxation spectra were tested with sample No. 40 as the representative, setting the $\mathrm{T}_{\mathrm{W}}$ value to $8 \mathrm{~s}$ and $\mathrm{T}_{\mathrm{E}}$ to $0.2,0.4$, 0.6 , and $0.8 \mathrm{~ms}$, respectively. Compared with the $0.2 \mathrm{~ms} \mathrm{NMR}$ signal, the samples lost $29.4 \%, 51.6 \%$, and $72.8 \%$ of the total NMR signals tested at $0.4,0.6$, and $0.8 \mathrm{~ms}$, respectively, and the signals of both large and small pores were lost simultaneously; the smaller the $T_{E}$ value, the more the curve is shifted to the left, and the less the amount of signal lost in small pores, as shown in Figure 3A. The $\mathrm{T}_{2}$ relaxation spectra were tested with sample No. 40 , setting the $\mathrm{T}_{\mathrm{E}}$ value to $0.2 \mathrm{~ms}$ and the $\mathrm{T}_{\mathrm{W}}$ value to $2,3,5$, and $8 \mathrm{~s}$, respectively; the total signal volume fluctuated within $2.9 \%$, and four curves had high overlap, as shown in Figure 3B. 

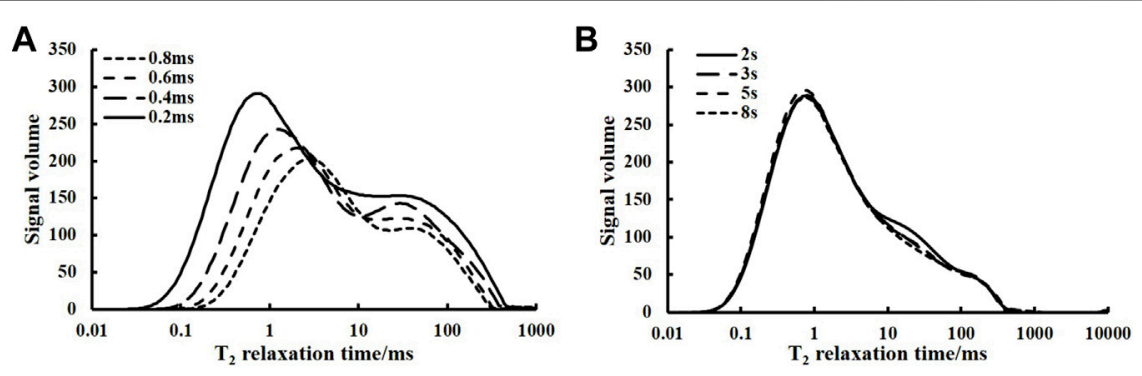

FIGURE 3 $\mid T_{2}$ spectra at different $T_{E}$ and $T_{W}$ values. (A) $T_{2}$ spectra influenced by $T_{E}$ and (B) $T_{2}$ spectra influenced by $T_{W}$.

The above results show that for tight sandstone samples, the $\mathrm{T}_{\mathrm{E}}$ value is the key to affecting the signal volume, and it is suggested that the $T_{E}$ value is taken to be less than $0.2 \mathrm{~ms}$, and the $\mathrm{T}_{\mathrm{W}}$ value has no obvious effect on the signal volume. This is because micro- and nanopores are developed in tight sandstone, and the NMR instrument can completely polarize the water in the pores with a short echo interval and waiting time, and the $\mathrm{T}_{\mathrm{W}}$ value can be consistent with the conventional NMR test range.

Eighteen dense sandstone samples (the porosity ranging from $5.8 \%$ to $10.7 \%$, with an average of $9.1 \%$ ) with known water saturation were selected and tested using the optimized NMR experimental parameters. Compared with the known water saturation, the relative errors of the results ranged from $0.2 \%$ to $14.6 \%$, with an average error of $4.8 \%$, as shown in Figure 2G. This indicates that the optimized NMR parameters can meet the requirements of the water saturation test.

\section{CONCLUSION}

The determination of water saturation by the constant weight method is basically consistent with the known water saturation with an average error of $3.6 \%$, indicating that the water saturation measured by the constant weight method can be used as a reference value for the determination of moisture content in rock.

By shortening the echo interval, the relative error of water saturation in tight sandstone tested by the NMR method ranged from $0.2 \%$ to $14.6 \%$, with an average error of $4.8 \%$. The $\mathrm{T}_{\mathrm{E}}$ value is the key to affecting the signal volume, and it is suggested that the $T_{E}$ value is taken to be no greater than $0.2 \mathrm{~ms}$, and the $T_{W}$ value can be consistent with the conventional NMR test range.

For the determination of water saturation in tight sandstone reservoirs, the constant gravity method and NMR method have high accuracy and meet the requirements of experimental testing quality, and the distillation extraction method and Coulomb method are not recommended.

\section{REFERENCES}

1. American Petroleum Institute Recommended Practices for Core Analysis. 2nd ed., 40. Washington: Recommended Practices (1998).

2. Handwerger DA, Willberg D, Pagels M, Rowland B. Reconciling Retort versus Dean Stark Measurements on Tight Shales. San Antonio, TX: SPE (2012). p. 159976.

\section{DATA AVAILABILITY STATEMENT}

The original contributions presented in the study are included in the article/Supplementary Material, further inquiries can be directed to the corresponding author.

\section{AUTHOR CONTRIBUTIONS}

The conception and design of the study were mainly contributed by CL and LM. The experiment and analysis were mainly contributed by $\mathrm{CL}$ and $\mathrm{BZ}$. The analysis and/or interpretation of data were mainly contributed by XL and YL. Drafting of the manuscript was mainly contributed by CL, DR, DL, and XT.

\section{FUNDING}

This study was financially supported by the National Natural Science Foundation of China (Nos. 51874240, 51934005, and 52074226) and Open Fund of Shaanxi Key Laboratory of Advanced Stimulation Technology for Oil \& Gas Reservoirs (No. 20JS120).

\section{ACKNOWLEDGMENTS}

We are grateful to Ting Deng, Xiaolong Cui and others for their help with the fieldwork.

\section{SUPPLEMENTARY MATERIAL}

The Supplementary Material for this article can be found online at: https://www.frontiersin.org/articles/10.3389/fphy.2022.833940/ full\#supplementary-material

3. Aggarwal SK, Johnston RH. Oil and Water Content Measurement of Sandstone Cores Using Microwave Measurement Techniques. IEEE Trans Instrum Meas (1986) IM-35:630-7. doi:10.1109/tim.1986.6831782

4. Zhao QH, Zhao XB, Zheng YL, Li JC, He L, Zou CJ. Microwave Fracturing of Water-Bearing Sandstones: Heating Characteristics and Bursting. Int J Rock Mech Mining Sci (2020) 136:104495. doi:10.1016/j.ijrmms.2020. 104495 
5. Tewari YB, Gery PD, Vaudin MD, Mighell AD, Klein R, Goldberg RN. Saturation Molalities and Standard Molar Enthalpies of Solution of Cytidine(cr), Hypoxanthine(cr), Thymidine(cr), Thymine(cr), Uridine(cr), and Xanthine(cr) in $\mathrm{H} 2 \mathrm{O}(\mathrm{l})$. The J Chem Thermodynamics (2004) 36: 645-58. doi:10.1016/j.jct.2004.04.005

6. Xu Z, Zhang J, Feng Z, Fang W, Wang F. Characteristics of Remaining Oil Viscosity in Water- and Polymer-Flooding Reservoirs in Daqing Oilfield. Sci China Ser D-earth Sci (2010) 53:72-83. doi:10.1007/s11430-009-0184-y

7. Coates GR, Xiao L-Z, Prammer MG. NMR Logging Principles and Applications (2000).

8. Mardon D, Prammer MG, Coates GR. Characterization of Light Hydrocarbon Reservoirs by Gradient-NMR Well Logging. Magn Reson Imaging (1996) 14: 769-77. doi:10.1016/S0730-725X(96)00162-2

9. Xuan D-Q, Fu S-Q, Xie R-H. Study on NMR Logging Bulk Volume of Irreducible Water Model. Nucl Elect Detect Tech (2007) 27:578-82. (in Chinese). doi:10.1007/978-3-540-72108-6_3

10. Mao Y, Chen Y, Xia W, Peng Y, Xie G. Understanding the Dynamic Pore Wetting by $1 \mathrm{H}$ LF-NMR Characterization. Part 1: Effect of Dynamic Viscosity of Liquid. Colloids Surf A: Physicochemical Eng Aspects (2021) 613:126039-11. doi:10.1016/j.colsurfa.2020.126039

11. Huang F-T, Cheng X-M, Shen P-S, Yin Q-A. Appraisal of Oil and Water Saturation Analysis Techniques and a Study of the Factors Affecting the Result of Analysis. (in Chinese). Petrol Explor Dev (1992) 19:69-78. CNKI:SUN: SKYK.0.1992-03-010.

12. Yu-hang G, Bao-zhi P, Li-hua Z, Chuan-hui F. Research and Application of the Relationship between Transverse Relaxation Time and Resistivity Index in Tight Sandstone Reservoir. J Pet Sci Eng (2018) 160:597-604. doi:10.1016/j. petrol.2017.01.034

13. Aboozar S, Abbas H, Mohammad J, Soleymanzadeh A, Helalizadeh A, Jamialahmadi M, et al. Development of a New Model for Prediction of Cementation Factor in Tight Gas Sandstones Based on Electrical Rock Typing. J Nat Gas Sci Eng (2021) 94:104128-9. doi:10.1016/j.jngse.2021. 104128

14. Li X, Li C, Li B, Liu X, Yuan C. Response Laws of Rock Electrical Property and Saturation Evaluation Method of Tight Sandstone. Pet Exploration Dev (2020) 47:214-24. doi:10.1016/S1876-3804(20)60020-9

15. Ma H, Gao S, Ye L, Liu H, Xiong W, Shi J, et al. Change of Water Saturation in Tight Sandstone Gas Reservoirs Near Wellbores. Nat Gas Industry B (2018) 5: 589-97. doi:10.1016/j.ngib.2018.11.007

16. Saxena N, Dietderich J, Alpak FO, Hows A, Appel M, Freeman J, et al. Estimating Electrical Cementation and Saturation Exponents Using Digital Rock Physics. J Pet Sci Eng (2021) 198:108198-11. doi:10.1016/j.petrol.2020. 108198

17. Wang S-Y, Tan M-J, Wang X-C, Zhang L-T. Microscopic Response Mechanism of Electrical Properties and Saturation Model Establishment in Fractured Carbonate Rocks. J Perol Sci Eng (2021) 208:1-12. doi:10.1016/j. petrol.2020.108198

18. Song Y, Li Z, Jiang Z, Luo Q, Liu D, Gao Z. Progress and Development Trend of Unconventional Oil and Gas Geological Research. Pet Exploration Dev (2017) 44:675-85. doi:10.1016/S1876-3804(17)30077-0

19. Nelson PH. Pore-throat Sizes in Sandstones, Tight Sandstones, and Shales. Bulletin (2009) 93:329-40. doi:10.1306/10240808059
20. Kong X, Xiao D, Jiang S, Lu S, Sun B, Wang J. Application of the Combination of High-Pressure Mercury Injection and Nuclear Magnetic Resonance to the Classification and Evaluation of Tight Sandstone Reservoirs: A Case Study of the Linxing Block in the Ordos Basin. Nat Gas Industry B (2020) 7(5):433-42. doi:10.1016/j.ngib.2020.09.001

21. Zheng D, Pang X, Jiang F, Liu T, Shao X, Huyan Y. Characteristics and Controlling Factors of Tight Sandstone Gas Reservoirs in the Upper Paleozoic Strata of Linxing Area in the Ordos Basin, China. J Nat Gas Sci Eng (2020) 75: 103135-21. doi:10.1016/j.jngse.2019.103135

22. Shu Y, Lin Y, Liu Y, Yu Z. Control of Magmatism on Gas Accumulation in Linxing Area, Ordos Basin, NW China: Evidence from Fluid Inclusions. J Pet Sci Eng (2019) 180:1077-87. doi:10.1016/j.petrol.2019.06.034

23. Wang P-Q, Chen D-K. The Determination of Water Content and Bound Water Type on Hydro-clay Surface by Thermal-weightlessness. J Southwest Petrol Inst (2006) 28:52-5. (in Chinese). doi:10.3863/j.issn.1000-2634.2006. 01.015

24. Wang Z-Z, Deng Y-M, Zhai S-D, Zhou L-F. Factors Affecting NMR $\mathrm{T}_{2}$ Spectra of Oil Well Samples and Methods for Determining the $\mathrm{T}_{2}$ Cutoff Value. Chin J Magn Reson (2006) 23:143-51. (in Chinese). doi:10.3969/j.issn.1000-4556. 2006.01.016

25. Li Z-T, Wang Z-Z, Zhao L. Nuclear Magnetic Resonance (NMR) Rock Sample Analysis Technology and the Application (2011). (in Chinese).

26. Xiao L-Z, Xie R-H, Liao G-Z. Theory and Method of Nuclear Magnetic Resonance Logging for Complex Reservoirs in China (2012). (in Chinese).

27. Kuang L-C, Sun Z-C, Mao Z-Q. Application of NMR in Junggar Basin Exploration and Development (2015). (in Chinese).

28. Liu D, Ren D, Du K, Qi Y, Ye F. Impacts of mineral Composition and Pore Structure on Spontaneous Imbibition in Tight sandstone. J Pet Sci Eng (2021) 201:108397. doi:10.1016/j.petrol.2021.108397

Conflict of Interest: Authors CL, LM, XL, YL, and BZ were employed by the company CNOOC EnerTech-Drilling \& Production Co. Authors CL, LM, XL, YL, and BZ were employed by the company CNOOC Energy Technology \& Services Limited.

The remaining authors declare that the research was conducted in the absence of any commercial or financial relationships that could be construed as a potential conflict of interest.

Publisher's Note: All claims expressed in this article are solely those of the authors and do not necessarily represent those of their affiliated organizations or those of the publisher, the editors, and the reviewers. Any product that may be evaluated in this article or claim that may be made by its manufacturer is not guaranteed or endorsed by the publisher.

Copyright $\odot 2022 \mathrm{Liu}, \mathrm{Ma}$, Liu, Li, Zhang, Ren, Liu and Tang. This is an open-access article distributed under the terms of the Creative Commons Attribution License (CC $B Y$ ). The use, distribution or reproduction in other forums is permitted, provided the original author(s) and the copyright owner(s) are credited and that the original publication in this journal is cited, in accordance with accepted academic practice. No use, distribution or reproduction is permitted which does not comply with these terms. 